Journal of Business \& Management (COES\&RJ-JBM)

ISSN (E): 2306-7179 ISSN (P): 2306-8043

Publisher: Centre of Excellence for Scientific \& Research Journalism, COES\&RJ LLC

Online Publication Date \& Issue: $1^{\text {st }}$ January 2016, Vol.4, No.1, January 2016

http://centreofexcellence.net/J/JBM/JBM\&20Mainpage.htm

\title{
Knowledge Sharing Capability: A Literature Review
}

Dr. Ra'ed (Moh'd Taisir) Masa'deh, Management Information Systems Department, School of Business, The University of Jordan, r.masadeh@ju.edu.jo

Eng. Ala'a Hamdi Gharaibeh, An Independent Researcher, Amman, Jordan, allaa_eng@yahoo.com

Dr. Ali Tarhini, Researcher, Department of Information Systems, Brunel University London, UK, ali.tarhini@hotmail.co.uk

Dr. Bader Yousef Obeidat, Associate Professor, Business Management Department, School of Business, The University of Jordan, b.obeidat@ju.edu.jo

\begin{abstract}
:
This paper is concerned with providing a deep theoretical analysis for the fields of knowledge sharing enablers and knowledge sharing capability. A historical overview of knowledge management is addressed at the beginning to provide the reader with an initial understanding of the concept. Then, knowledge sharing enablers as well as knowledge sharing capability concepts are reviewed. Also, the links among knowledge sharing enablers, knowledge sharing capability, and firm performance are discussed through theoretical and empirical studies. This study will be useful for both academia and practitioners as to fill the gap of the incomplete causal chains between knowledge sharing and knowledge sharing capability.
\end{abstract}

Keywords:

Knowledge sharing capability, knowledge sharing enablers, knowledge management

\section{Citation:}

Masa'deh, Dr. Ra'ed (Moh'd Taiser); Gharaibeh, Eng. Ala'a Hamdi; Tarhini, Dr. Ali; Obeidat, Dr. Bader yousef Obeidat (2016; Knowledge sharing capability: a literature review; Journal of Business \& Management (COES\&RJ-JBM) Vol.4, No.1, pp.1-13. 


\section{Introduction}

Several researchers emphasize the role of Knowledge Management (KM) and its processes in achieving organizational competitive advantages (e.g., Lee and Choi, 2003; Shannak et al., 2010; Altamony et al. 2012; Masa'deh, 2012; Gharaibeh, 2013; Kannan et al., 2013; Masa'deh et al., 2014; Obeidat et al., 2014). Becerra-Fernandez and Sabherwal (2010) earlier defined knowledge management as performing the activities involved in discovering, capturing, sharing, and applying knowledge so as to enhance, in a cost-effective fashion, the impact of knowledge on the unit's goal achievement. Further, knowledge management depends on four main types of processes. These include the processes through which knowledge is discovered or captured and processes through which knowledge is shared and applied. Indeed, discovering knowledge is defined as the development of new tacit or explicit knowledge from data and information or from the synthesis of prior knowledge. While capturing knowledge is defined as the process of retrieving either explicit or tacit knowledge that resides within people, artifacts, or organizational entities and knowledge reside outside the organizational boundaries including consultants, competitors, customers, suppliers, and prior employers of the organization's new employees.

Many researchers (e.g., Rivera-Vazquez et al. 2009; Mishra and Bhaskar, 2011; Pinho et al. 2012; Masa'deh et al., 2013a) have called for further research to identify the antecedents that enhance the occurrence of knowledge sharing, while others (e.g., Kamasak and Bulutlar, 2010; Mills and Smith, 2011; Wu et al. 2012) have stressed the need to study the effect of knowledge sharing on firm performance. Therefore, in order to respond to some scholars' calls for further research in the field, and since few previous research has investigated the knowledge sharing area; this research comes to review the relationships among knowledge sharing antecedents, knowledge sharing capability, and firm performance. Such a review is expected to be valuable for companies and might be considered as a guideline to enhance how companies could provide knowledge sharing between knowledge workers that suit their needs, requirements, and the regulators on a competitive base.

The rest of this paper is organized as follows. It commences with the background regarding knowledge sharing capability and its relation to knowledge management. Then, theoretical and empirical previous researches are reviewed during 2003 until 2014 on the links among knowledge sharing enablers, knowledge sharing capability, and firm performance. Finally, the discussion and conclusion are then stated and areas for future research are also provided.

\section{Knowledge Management and Knowledge Sharing Capability}

Becerra-Fernandez and Sabherwal (2010) defined knowledge management as doing what is needed to get the most out of knowledge resources. They added that KM is viewed as a discipline that promotes the creation, sharing, and leveraging of the corporation's knowledge. Further, knowledge management performs several activities as conducting, discovering, capturing, sharing, and applying knowledge. Indeed, sharing knowledge is defined as the process by which explicit or tacit knowledge can flow between individuals, or utilize from others as groups, departments, or organizations. The flow of knowledge (whether explicit or tacit) among individuals depends on the use of exchange or socialization processes. Socialization facilitates the sharing of tacit knowledge in a case in which new tacit knowledge could be created. There is no intrinsic difference between the socialization process when it is used for knowledge discovery or knowledge sharing, although the way in which the process may be used could be different (Becerra-Fernandez and Sabherwal, 2010).

Furthermore, knowledge sharing which was defined as the process through which explicit or tacit knowledge is communicated to other individuals (Becerra-Fernandez and Sabherwal, 2010); can be clarified by three points. First, knowledge sharing means effective transfer, so that the recipient of knowledge can understand it well enough to act on it. Second, what is 
shared is knowledge rather than recommendations based on the knowledge; the former involves the recipient acquiring the shared knowledge as well as being able to take action based on it, which simply involves utilization of knowledge without the recipient internalizing the shared knowledge. Third, knowledge sharing may take place across individuals as well as across groups, departments, or organizations (Jensen and Meckling 1996; Alavi and Leidner 2001). Thus, sharing knowledge is an important process in enhancing organizational innovativeness and performance.

According to Friesl et al. (2011), knowledge sharing is considered as a process in which one unit is affected by the knowledge and expertise of another unit. Furthermore, they consider the extent to which such units use and build on each other's knowledge an important part of knowledge sharing which may occur through formal collaboration or in informal everyday interaction. However, according to $\mathrm{Wu}$ and $\mathrm{Zhu}$ (2012), there is no all-round definition of knowledge sharing. They commented that many researchers have defined knowledge sharing from their own point of view. Some considered it as knowledge flows and knowledge transfer as exchangeable terms; while others depicts knowledge sharing to knowledge transfer and defined it as the process of disseminating knowledge throughout the organization, in which the dissemination can happen between individuals, groups or organizations using any type or number of communication channels. Also, Wu and Zhu (2012) stated that knowledge flows including five elements: value of the source knowledge, willingness of the source to share knowledge, media richness of the communication channel, willingness of the recipient to acquire knowledge, and the absorptive capacity of the recipient.

\section{Literature Review}

Masa'deh et al. (2015) argued that knowledge management processes, mainly knowledge sharing, have been well thought-out as a major practice for all organizations, public and private. As well, the ways in which such organizations deal and value the richness of their knowledge sharing capabilities which in turn affect their performance are required. Consequently, the researchers suggested a theoretical model by which both transformational and transactional leadership styles influence employees' knowledge sharing practices, and the effect of the latter on job performance, and then on firm performance.

Vij and Farooq (2014) examined the impact of Knowledge Sharing Orientation (KSO) of business on its performance. A purposive sample of 300 key informants (CEOs, top level and middle level managers who were key decision makers in the organizations) from several manufacturing and service organizations has been considered from the National Capital Region (NCR) in India. The scales used for the survey were validated using Confirmatory Factor Analysis before applying Structural Equation Modeling for studying the relationships. The relative performance of the organization compared to the major competitor for the last three years has been considered as the measure for business performance. The researchers hypothesized relationships between KSO and business performance for two multi-group moderators, including firm size (based on number of employees/based on investment) and nature of industry. The results indicated that KSO significantly and positively impacts business performance. Also, firm size significantly moderates the relationship between KSO and business performance. The findings of the study could help knowledge management researchers and practitioners in formulating strategies for better business performance.

Wang et al. (2014) aimed to study the impact of knowledge sharing on firm performance and the mediating role of intellectual capital. 228 usable responses were collected from high technology firms in China. Structural equation modelling (SEM) was employed to test the research model. The researchers found that tacit knowledge sharing significantly contributed to all three components of intellectual capital, namely human, structural and relational capital; whereas explicit knowledge sharing only has a significant impact on human and structural 
capital. Also, human, structural and relational capital has improved both operational and financial performance of firms. Consequently, the impact of knowledge sharing on firm performance was mediated by intellectual capital. Moreover, while explicit knowledge sharing has a greater effect on financial performance than operational performance, tacit knowledge sharing has a greater impact on operational performance than financial performance.

Masa'deh et al. (2013b) investigated the impact of knowledge sharing enablers on knowledge sharing capability, and firm performance mediated by innovation capability. The population of the study consists of telecommunication employees in Jordan (Orange, and Umniah), which counts for 3500 employees. Moreover, since the researchers were not allowed to contact directly the employees in the two companies, Human Resource (HR) managers were informed in which they could choose the respondents randomly from all managerial levels (i.e. senior management, middle management, operational management, and staff). Consequently, questionnaires were distributed to the HR managers who then gave them to potential respondents. Furthermore, 367 surveys were returned. The study employed Structural Equation Modeling (SEM) techniques with Analysis of Moment Structures (AMOS) 6 software for data analysis. The results of the path coefficient revealed that knowledge sharing enablers (i.e. enjoyment in helping others, top management support, organizational rewards, and ICT use) had a significant influence on employees' knowledge sharing capability; whereas knowledge self-efficacy did not. Also, the study did not find a direct relationship between knowledge sharing capability and firm performance. Nevertheless, causal links were found between knowledge sharing capability and innovation capability; and innovation capability and firm performance.

An empirical study was led by Tuan (2013) to examine if corporate social responsibility (CSR) influences trust, which in turn engenders the chain of effects from upward influence behaviour through organizational health to knowledge sharing. The research contribution was between ethical CSR and identification-based trust or knowledge-based trust, which positively corresponds to organizationally beneficial upward influence behaviour, but negatively corresponds to self-indulgent behaviour or destructive behaviour. A structural equation modelling (SEM) approach was employed which contributed to the analysis of 412 responses returned from self-administered structured questionnaires sent to 635 middle level managers. The researcher found that CSR, trust, and upward influence behaviour have an impact on organizational health and the direction of the mediated relationship of upward influence behaviour and organizational health may work in reverse; and that organizational health is strongly related to knowledge sharing.

Kumar and Rose (2012) examined the factors that contribute to knowledge sharing behaviour and subsequently examined the combined effects of IWE (Islamic Work Ethics) on innovation capability in the Malaysian public sector organizations. They defined knowledge sharing as a human behaviour which apprehends activities such as exchanging explicit and/or implicit experiences, embedding ideas and skills that facilitate knowledge for innovation at workplace. They focused on the knowledge sharing enablers and its impacts on knowledge sharing capability and innovation. The researchers identified seven antecedents of knowledge sharing: enjoyment in helping others, reciprocity, self-image, knowledge self-efficacy, pro-sharing norms, generalized trust and reward systems. Based on 472 Administrative and Diplomatic Service Officers from the Malaysian public sector organizations participated in the survey, the empirical results revealed that the intrinsic motivation to share knowledge is significant in the public sector organizations. The relationship between knowledge sharing capability and innovation capability of employees in the public sector organizations was found to be contingent on IWE, they found the intrinsic motivation to share knowledge was significant in the public sector organizations, such as enjoyment in helping others, self-efficacy and 
generalized trust. Therefore, the sense of belongingness and pledge of the Administrative and Diplomatic Service officers perhaps can be a prerequisite to engage in knowledge sharing activities. They proved that the relationship between knowledge sharing capability and innovation capability was moderately influenced by IWE. Greater innovation means public sector organizations will be more resilient in responding to changing environments and reaching desired outcomes.

A recent research was conducted by Lavanya (2012) to analyze the antecedents of knowledge sharing. 750 questionnaires were distributed, and only 516 fulfilled the condition of the study. The researcher argued that many companies are identifying, managing and sharing the experience of employees to accelerate the knowledge sharing market; and is useful only when it is put into action. Lavanya (2012) found that knowledge sharing was affected by the following factors: attitude, trust, perceived time pressure, organizational knowledge ownership, organizational culture, knowledge management initiative and absorptive capacity. Moreover, the study concluded that before developing information and communication technology solutions for knowledge management; companies need to understand what knowledge they have, what knowledge they need, and who knows about what, and apply the technology appropriately.

Mueller (2012) aimed to study Knowledge sharing between project teams and cultural antecedents. The research design used a triangulation of methods (interviews, observations, company data and group discussions) to receive detailed results for the study. The researcher found that knowledge sharing between project teams took place even though top management did not include these processes in the formal work organization. The researcher found that project team leaders and members share knowledge with other project teams by transferring boundary objects, interchanging team members and directly interacting. In addition, the study approved some elements of a knowledge culture, and also discovered new cultural elements to knowledge sharing between teams, such as personal responsibility, intrinsic motivation, top management's trust in employees, and output orientation.

According to Sáenz et al. (2012), to make knowledge sharing possible, there are different mechanisms and initiatives used as facilitators. Many of these mechanisms take advantage of information and communication technologies (on-line discussion forums, blogs, intranets and knowledge repositories) whereas, in other cases, personal interaction between individuals is the key (communities of practice, coaching, mentoring and employee functional rotation, to name but a few), this does not mean that all knowledge is shared through them for example: knowledge exchange can take place naturally, as a part of daily management processes. Therefore, the researcher investigated the influence of each type of knowledge sharing mechanism (ICT-based, personal interaction-based and embedded in management processes) on innovation capability. Indeed, innovation lies at the core of what is known as "dynamic capabilities", Sáenz et al. (2012) tested empirically the degree of influence of different knowledge sharing mechanisms (ICT-based, personal interaction-based, and embedded in management processes) on innovation capability, as well as the influence of each first-level innovation capacity on company performance. Sáenz et al. (2012) found that knowledge sharing was a key issue in order to enhance innovation capability and company performance.

According to Sharma et al. (2012), rapid changes due to globalization in the business environment caused by intense competition creates competitive business environment, thus knowledge becomes the key component of competitive advantage and the main factor to enhance productivity and improved organizations. Indeed, knowledge sharing is considered as a basic facilitator for knowledge management which helps in achieving organization goals although knowledge sharing barriers can obstruct the effectiveness of KM. Sharma et al. (2012) studied 22 barriers of knowledge sharing including lack of top management support, 
concept of $\mathrm{KM}$ is not well understood, lack of integration of $\mathrm{KM}$ strategy, lack of infrastructure supporting KS, lack of transparent rewards, lack of organizational culture, emphasis on individuals rather than teams, lack of knowledge retention, staff defection and retirement, lack of documentation, lack of social network, insufficient analysis of past mistakes, lack of time to share knowledge, fear of job security, lack of trust, age differences, gender differences, differences in national culture, lack of training, unrealistic expectations of employees, reluctance to use IT system, and lack of integration of IT system. Sharma et al. (2012) found that top management's commitment and their understanding towards the concept of KM plays a significant role and work as the main driver in the successful implementation of KM.

Wu et al. (2012) examined the relationship between adventure recreation, knowledge sharing, and firm performance. They tested the influence of knowledge sharing on the performance of information system $R \& D$ personnel by introducing adventure recreation as a mediating variable to find out the association. They found that the sharing of system structure and task knowledge positively and significantly influence task performance and group performance, whereas interpersonal relationship knowledge sharing positively and significantly influences group performance. Furthermore, adventure recreation was a mediating variable between knowledge sharing and performance, members' sharing of task and system structure-related knowledge positively influenced performance.

Kamasak and Bulutlar (2010) explored the effects of knowledge sharing on innovation. They examined two forms of knowledge sharing, knowledge donating and knowledge collecting. Further, the effects of knowledge donating and collecting on ambidexterity in organizations are also studied, in which ambidexterity is defined as the simultaneous achievement of exploratory and exploitative innovation. A questionnaire was used to collect data from 246 middle and top-level managers in Turkey designed to measure the relationship between knowledge sharing and innovation. They found that knowledge collecting had a significant effect on all types of innovation and ambidexterity, while knowledge donating, involving donating inside and outside the group, did not have any effect on exploratory innovation.

A research was conducted by Rivera-Vazquez et al. (2009) to investigate overcoming cultural barriers for innovation and knowledge sharing. A qualitative research was used that consisted of interviews which were carried out to management personnel and questionnaires which were submitted to employees using the results collected from four public and private organizations. The researchers argued that organizations must identify and overcome some cultural barriers to be effective in producing and sharing knowledge at the micro level which has to do with the organizational culture as it is shaped by national culture of citizens working for the organization. Rivera-Vazquez et al. (2009) found that from the interview responses, the managerial level both in private and public agencies have overcome the barriers that set back the sharing of knowledge, while the questionnaires found that at the employee level several cultural barriers such as organizational environment, emotional intelligence and managers' commitment are still present. Moreover, the researchers recommended that this study may be used to develop standard procedures to cope with culture differences when establishing a suitable environment for knowledge production and sharing among employees.

Almaddan (2008) aimed to measure the impact of organizational culture factors on the implementation of knowledge management in Orange Jordan Telecommunication Group. The total number of employees was (2700), the sample analysis included (270) employees at all levels which were selected randomly, and the researcher found that: there is an effect of cultural executive on knowledge management, and an organizational culture effect on knowledge management. Also, the leadership variable had the most effect on knowledge management; the other impacted factors on knowledge management were as following 
(workers, incentive systems, organizational processes, organizational structure, and information systems). The researcher also recommended that top management should adopt a strategy for managing incentive systems to encourage workers to be creative and innovative; and encouraging them to generate knowledge in order to improve performance and enable organizational creativity and innovation.

Albatyneh (2007) tested three main hypotheses: the first hypothesis examined if there is an impact of the knowledge site on performance and organizational learning, the second hypothesis concerned if there is an impact of knowledge management, which includes the organizational structure and organizational culture, infrastructure, information technology on organizational performance and organizational learning; and the third hypothesis related to the effect of the exercise of knowledge management practices (i.e. the diagnosis, the acquisition and generation, storage and distribution, and application of knowledge) on organizational performance and organizational learning. The study was applied on (15) Jordanian Commercial Banks where questionnaires were distributed and in which (114) were used in the analysis. The researcher recommended that banks should encourage individuals to carry out KM initiatives concerning individuals, setting goals, exploiting the availability of experts in the field of knowledge, and modifying the organizational structure and the availability of infrastructure for information technology and operations concerning the diagnosis and knowledge acquisition.

Lin (2007) conducted a research to analyze Knowledge sharing and firm innovation capability. 172 surveys were distributed to employees from 50 large organizations in Taiwan; the structural equation modelling (SEM) was used to investigate the research model. The researcher argued that the relationships among knowledge-sharing enablers, processes, and firm innovation capability may provide a clue regarding how firms can promote knowledgesharing culture to sustain their innovative performance. Lin (2007) found that knowledge sharing processes were influenced by individual factors (enjoyment in helping others and knowledge self-efficacy), organizational factors (top management support and organizational rewards) and technology factors (information and communication technology use) and whether more leads to superior firm innovation capability. Moreover, firm innovation capability was found to be strongly positively associated with employee willingness to donate and collect knowledge. They recommended that more research can examine how personal traits (such as age, level of education, and working experiences) and organizational characteristics (such as firm size and industry type) may moderate the relationships between knowledge enablers and processes.

Moreover, some researchers argued that a firm that adopts KM practices can obtain superior firm performance. For example, an empirical study was led by McKeen et al. (2006) to test the effect of KM on organizational performance. They defined KM practices as observable organizational activities that are related to knowledge management. They focused on the extent of KM practices and their relationship with the outcomes. The researchers identified four dimensions of $\mathrm{KM}$ practices that are related to performance: the ability to locate and share existing knowledge; the ability to experiment and create new knowledge; a culture that encourages knowledge creation and sharing; and a regard for the strategic value of knowledge and learning. Based on 90 Canadian, US, and Australian firms, representing ten different industry sectors, they found that KM practices correlate directly with several intermediate measures of organizational performance, such as customer intimacy (formed by merging customer satisfaction and customer retention); product leadership (formed by merging innovation and rate of new product development); and operational excellence, which in turn are directly related to firm performance indicators like ROA, ROE, and profitability. Therefore, they encouraged practitioners to concentrate on specific intermediate endings and 
the timing of KM initiative launches. They concluded, yet, that more research is required to validate their results.

In addition, Keskin (2005) tested the associations among explicit-orientated KM strategy, tacit-oriented KM strategy, and firm performance. These associations were moderated by the environmental hostility factor, which entails environmental turbulence (i.e. unexpected changes in environmental conditions) and the intensity of market competition. Explicit and tacit knowledge management strategies were found to be positively and significantly associated with firm performance. Furthermore, the study revealed that the more the environmental hostility, the greater the association between explicit and tacit-orientated KM strategies, and firm performance.

A research was conducted by Darroch (2005) to test the role of KM in firms. Mail surveys of 443 CEO's in large New Zealand firms were used to investigate the links among KM, innovation, and firm performance. KM was measured by looking at three main constructs: knowledge acquisition, knowledge dissemination, and responsiveness to knowledge. Seven factors characterized knowledge acquisition: valuing employees' attitudes and opinions and encouraging employees to up-skill; having a well-developed financial reporting system; being market-focused by actively obtaining customer and industry information; being sensitive to information about changes in the marketplace; employing and retaining a large number of people trained in science, engineering, or math; working in partnership with international customers; and getting information from market surveys. Knowledge dissemination was measured by two factors: readily disseminating market information around the organization; and using technology such as teleconferencing and videoconferencing to facilitate communication. Moreover, responsiveness to knowledge was achieved by five factors: responding to knowledge about customers, competitors, and strategies; being flexible with readily-changeable products; using innovation to create new products for the firm; improvements to existing product lines; and cost reduction of existing products. Also, innovation was measured by asking firms the extent to which they add new products to the world and to the firm, how they add to existing product lines, how they improve or revise to existing product lines, how they achieve cost reductions on existing products, and how they reposition existing products. Firm performance was evaluated by accounting measures such as profits, and non-accounting measures like market share and sales growth. Darroch (2005) found that firms with KM capability that used resources much more efficiently, and in more innovative ways, were achieving higher returns than others.

Alomary (2004) conducted a research on commercial banks of Jordan to study the joint use of information technology and knowledge management to achieve high value on the work of banks, data were collected from (116) manager, experts, and consultants working in (16) commercial Jordanian banks, in which the research found a strong relationship between knowledge management and high value works at the researched banks, and a strong relationship between information technology and the high value of the work. Also the study found that there is a strong relationship between the joint use of knowledge management, information technology and high value to the work of the commercial banks. Further, the researcher recommended to take advantage of the World Wide Web (Internet) in the provision of services and enhancing the value-added, to use decision support systems and expert systems, and pay greater attention to motivation and satisfaction of employees and support the achievements of users in addition to recommending the use of knowledge management in all the banks to achieve high value for their work.

Choi and Lee (2003) found that explicit KM (relating to knowledge codification, acquisition and sharing in codified forms and documentation) and tacit KM (relating to the knowledge acquisition from experts and knowledge sharing by one-to-one connections) could lead to 
differences in firm performance. In other words, an explicit KM strategy can result in growth and productivity, while a tacit KM strategy is crucial for innovation.

To sum up, a comprehensive literature review is addressed on knowledge sharing enablers and knowledge sharing capability during 2003 until 2014. Also, theoretical and empirical review on the links among knowledge sharing enablers, knowledge sharing capability, and firm performance are provided.

\section{Conclusion}

The contributions of this study will be useful for both academics and practitioners. From the academic perspective, this study aspires to fill the gap of the incomplete causal chains between knowledge sharing and knowledge sharing capability. Furthermore, because most knowledge sharing literature is theoretical and lacks empirical evidence (see Chatti, 2012; Kumar and Rose, 2012; Sáenz et al. 2012), the current study does not only provide a holistic review of the extant literature on knowledge sharing, but it is also the first research of its nature to reveal the causal chains of knowledge sharing. Furthermore, from the industry practitioner's perspective, this study is of interest to IT managers and business managers in terms of their real relationships with their employees. It also helps them to adopt the best practices for managing knowledge sharing in the firms they work for. IT and business senior management also needs to recognize the knowledge sharing mechanisms in which they may well transform their IT preferences into operational decision making. Consequently, the study provides useful and practical guidelines to IT managers and business managers to understand the resources and conditions required to realize the potential values of their IT investments in terms of innovation capabilities, and business-based performance.

Furthermore, since organizational culture is defined as the specific collection of values and norms that are shared by people and groups in an organization and that control the way they interact with each other and with stakeholders outside the organization (Al Azmi et al., 2012; Alkalha et al., 2012; Obeidat et al. 2012; Shannak et al. 2012a), the current research is expected to enrich the knowledge when it comes to the concept of knowledge sharing for understanding the cultural factors among others of knowledge sharing antecedents on knowledge sharing capability.

Moreover, as mentioned by Sekaran (2003) and Sekaran and Bougie (2013) that an interpretive position, which is an inductive approach, disputes that statistical patterns or correlations are not understandable on their own. Accordingly, it is necessary to uncover what meaning people give to the actions that lead to such patterns. For this and based on reviewing the literature in the current study, it has been found that most studies are either theoretical or deductive in nature, and thus more inductive research is required.

Although reliability is considered as a necessary condition of the test of goodness of the measure used in research, it is not sufficient (Hair et al., 1998; Creswell, 2003; Creswell, 2008; Sekaran and Bougie, 2013; Saunders et al., 2007; Saunders et al., 2009; Hair et al., 2010), thus validity can be referred to as another condition used to measure the goodness of a measure. Furthermore, several researchers (e.g. Masa'deh and Shannak, 2012; Shannak et al., 2012b; Shannak et al., 2012c; Masa'deh, 2013; Masa'deh et al., 2013b) have called for more validation of the knowledge sharing construct besides its antecedents and outcomes. Nevertheless, reviewing the previous literature concerning knowledge sharing shows a lack of validity concerning this issue, its antecedents, and its outcome. Consequently, intended researches in the knowledge sharing domain should take into consideration these issues accurately. 


\section{References}

Al Azmi, N., Al-Lozi, M., Al-Zu'bi, Z., Dahiyat, S., and Masa'deh, R. (2012). Patients Attitudes toward Service Quality and its Impact on their Satisfaction in Physical Therapy in KSA Hospitals. European Journal of Social Sciences, 34 (2), pp. 300-314.

Alavi, M., and Leidner, D. (2001). Review: Knowledge Management and Knowledge Management Systems: Conceptual Foundations and Research Issues. MIS Quarterly, 25 (1), pp.107-136.

Albatyneh, M. (2007). The impact of knowledge management on performance and organizational learning in the Jordanian commercial banks. Unpublished PhD. Thesis, Amman Arab University, Amman, Jordan.

Alkalha, Z., Al-Zu'bi, Z., Al-Dmour, H., Alshurideh, M., and Masa'deh, R. (2012). Investigating the Effects of Human Resource Policies on Organizational Performance: An Empirical Study on Commercial Banks Operating in Jordan. European Journal of Economics, Finance and Administrative Sciences, 51 (August), pp. 44-64.

Almaddan, S. (2008). Measuring the impact of organizational culture factors in the implementation of knowledge management in the Jordan telecom group (Orange). Unpublished MSc. Thesis, Amman Arab University, Amman, Jordan.

Alomary, G. (2004). The shared use of information technology and knowledge management to achieve a high value to the work of Jordanian commercial banks. Unpublished PhD. Thesis, Amman Arab University, Amman, Jordan.

Altamony, H., Masa'deh, R, Alshurideh, M., and Obeidat, B. (2012). Information Systems for Competitive Advantage: Implementation of an Organisational Strategic Management Process. In the Proceedings of the 18th IBIMA Conference on Innovation and Sustainable Economic Competitive Advantage: From Regional Development to World Economic, Istanbul, Turkey, 9th-10th May.

Becerra-Fernandez, I., and Sabherwal, R. (2010). Knowledge Management: Systems and Processes, M.E. Sharpe Inc, New York.

Chatti, M. (2012). Knowledge Management: A Personal Knowledge Network Perspective. Journal of Knowledge Management, 16 (5), pp. 829-844.

Choi, B., and Lee, H. (2003). An Empirical Investigation of KM Styles and their Effect on Corporate Performance. Information \& Management, 40, pp. 403-417.

Creswell, J. (2003). Research Design: Qualitative, Quantitative, and Mixed Methods Approaches, 2nd edition, Thousand Oaks: Sage Publications.

Creswell, J. (2008). Research Design: Qualitative, Quantitative, and Mixed Methods Approaches. Los Angeles: Sage Publications.

Darroch, J. (2005). Knowledge Management Innovation and Firm Performance. Journal of Knowledge Management, 9 (3), pp. 101-115. 
Friesl, M., Sackmann, S., and Kremser, S. (2011). Knowledge Sharing in New Organizational Entities: The Impact of Hierarchy, Organizational Context, Micro-Politics and Suspicion. Cross Cultural Management: An International Journal, 18 (1), pp. 71-86.

Gharaibeh, A. (2013). The Impact of Knowledge Sharing Enablers on Knowledge Sharing Capability: An Empirical Study on Jordanian Telecommunication Firms. Unpublished MSc. Thesis, Amman Arab University, Jordan.

Hair, J., Anderson, R., Tatham, R., and Black, W. (1998). Multivariate Data Analysis, 5th edition, New Jersey: Prentice-Hall International Inc.

Hair, J., Black, W., Babin, B., Anderson, R., and Tatham, R. (2010). Multivariate Data Analysis. Upper Saddle River, New Jersey: Pearson Prentice Hall, Pearson Education, Inc

Jensen, M.C., and Meckling, W.H. (1996). Specific and General Knowledge, and Organizational Structure. In Knowledge Management \& Organizational Design, ed. P.S. Myers, 17-38. Newton, MA: Butterworth-Heinemann.

Kamasak, R., and Bulutlar, F. (2010). The Influence of Knowledge Sharing on Innovation. European Business Review, 22 (3), pp. 306-317.

Kanaan, R., Masa'deh, R., and Gharaibeh, A. (2013). The Impact of Knowledge Sharing Enablers on Knowledge Sharing Capability: An Empirical Study on Jordanian Telecommunication Firms. European Scientific Journal, 9 (22), pp. 237-258.

Keskin, H. (2005).The Relationship between Explicit and Tacit Oriented KM Strategy and Firm Performance. Journal of American Academy of Business, Cambridge, 7 (1), pp. 169175.

Kumar, N., and Rose, R. (2012). The Impact of Knowledge Sharing and Islamic Work Ethic on Innovation Capability. Cross Cultural Management, 19 (2), pp. 142-165.

Lavanya, B. (2012). Antecedents of Knowledge Sharing. International Journal of Business Insights and Transformation, 5 (2), pp. 403-417.

Lee, H. and Choi, B. (2003). Knowledge Management Enablers, Processes, and Organizational Performance: An Integrative View and Empirical Examination. Journal of Management Information Systems, 20 (1), pp. 179-228.

Lin, H. (2007). Knowledge Sharing and Firm Innovation Capability: An Empirical Study. International Journal of Manpower, 28 (3), pp. 315-332.

Masa'deh, R. (2012). The Impact of Management Information Systems (MIS) on Quality Assurance (QA): A Case Study in Jordan. International Journal of Information, Business and Management, 4 (2), pp. 93-110.

Masa'deh, R. (2013). The Impact of Information Technology Infrastructure Flexibility on Firm Performance: An Empirical Study of Jordanian Public Shareholding Firms. Jordan Journal of Business Administration, 9 (1), pp. 204-224.

Masa'deh, R., and Shannak, R. (2012). Intermediary Effects of Knowledge Management Strategy and Learning Orientation on Strategic Alignment and Firm Performance. Research Journal of International Studies, 24, pp. 112-128. 
Masa'deh, R., Gharaibeh, A., Maqableh, M., and Karajeh, H. (2013b). An Empirical Study of Antecedents and Outcomes of Knowledge Sharing Capability in Jordanian Telecommunication Firms: A Structural Equation Modeling Approach. Life Science Journal, 10 (4), pp. 2284-2296.

Masa'deh, R., Maqableh, M., and Karajeh, H. (2014). A Theoretical Perspective on the Relationship between Leadership Development, Knowledge Management Capability, and Firm Performance. Asian Social Science, 10 (6), pp. 128-137.

Masa'deh, R., Obeidat, B., Zyod, D., and Gharaibeh, A. (2015). The Associations among Transformational Leadership, Transactional Leadership, Knowledge Sharing, Job Performance, and Firm Performance: A Theoretical Model. Journal of Social Sciences (COES\&RJ-JSS), 4 (2), pp. 848-866.

Masa'deh, R., Shannak, R., and Maqableh, M. (2013a). A Structural Equation Modeling Approach for Determining Antecedents and Outcomes of Students' Attitude toward Mobile Commerce Adoption. Life Science Journal, 10 (4), pp. 2321-2333.

Mckeen, J., Zack, M., and Singh, S. (2006). Knowledge Management and Organizational Performance: An Exploratory Survey. In the Proceedings of the 39th Hawaii International Conference on System Sciences, pp. 1-9.

Mills, A., and Smith, T. (2011). Knowledge Management and Organizational Performance: A Decomposed View. Journal of Knowledge Management, 15 (1), pp. 156-171.

Mishra, B., and Bhaskar, A. (2011). Knowledge Management Process in Two Learning Organizations. Journal of Knowledge Management, 15 (2), pp. 344-359.

Mueller, J. (2012). Knowledge Sharing Between Project Teams and its Cultural Antecedents . Journal of Knowledge Management, 16 (3), pp. 435-447.

Obeidat, B., Masa'deh, R., and Abdallah, A. (2014). The Relationships among Human Resource Management Practices, Organizational Commitment, and Knowledge Management Processes: A Structural Equation Modeling Approach. International Journal of Business and Management, 9 (3), pp. 9-26.

Obeidat, B., Shannak, R., Masa'deh, R. and Al-Jarrah, I. (2012). Toward Better Understanding for Arabian Culture: Implications Based on Hofstede's Cultural Model. European Journal of Social Sciences, 28 (4), pp. 512-522.

Pinho, I., Rego, A., and Cunha, M. (2012). Improving Knowledge Management Processes: A Hybrid Positive Approach. Journal of Knowledge Management, 16 (2), pp. 215-242.

Rivera-Vazquez, J., Ortiz-Fournier, L., and Flores, F. (2009). Overcoming Cultural Barriers for Innovation and Knowledge Sharing. Journal of Knowledge Management, 13 (5), pp. 257-270.

Sáenz, J., Aramburu, N., and Blanco, C. (2012). Knowledge Sharing and Innovation in Spanish and Colombian High-Tech Firms. Journal of Knowledge Management, 16 (6), pp. 919-933.

Saunders, M., Lewis, P., and Thornhill, A. (2007). Research Methods for Business Students, 4th Edition. Edinburgh Gate, Harlow: Financial Times Prentice Hall. 
Saunders, M., Lewis, P., and Thornhill, A. (2009). Research Methods for Business Students, Financial Times Prentice Hall.

Sharma, B., Singh, M., and Neha. (2012). Knowledge Sharing Barriers: An Approach of Interpretive Structural Modeling. Journal of Knowledge Management, X (3), pp. 35-52.

Sekaran, U. (2003). Research Methods for Business: A Skill-Building Approach, 4th Edition. John Wiley and Sons, Inc.

Sekaran, U., and Bougie, R. (2013). Research Methods for Business: A Skill-Building Approach, 6th Edition. John Wiley and Sons, Inc.

Shannak, R., Masa'deh, R., Al-Zu'bi, Z., Obeidat, B., Alshurideh, M., and Altamony, H. (2012b). A Theoretical Perspective on the Relationship between Knowledge Management Systems, Customer Knowledge Management, and Firm Competitive Advantage. European Journal of Social Sciences, 32 (4), pp. 520-532.

Shannak, R., Masa'deh, R., and Akour, M. (2012c). Knowledge Management Strategy Building: Literature Review. European Scientific Journal, 8 (15), pp. 143-168.

Shannak, R., Obeidat, B., and Masa'deh, R. (2012a). Culture and the Implementation Process of Strategic Decisions in Jordan. Journal of Management Research, 4 (4), pp. 257-281.

Shannak, R., Masa'deh, R., Obeidat, B., and Almajali, D. (2010). Information Technology Investments: A Literature Review. In the Proceedings of the 14th IBIMA Conference on Global Business Transformation through Innovation and Knowledge Management: An Academic Perspective, Istanbul-Turkey, 23rd-24th June, pp.1356-1368.

Tuan, L. (2013). Underneath Organizational Health and Knowledge Sharing. Journal of Organizational Management, 26 (1), pp. 139-168.

Vij, S., and Farooq, R. (2014). Knowledge Sharing Orientation and Its Relationship with Business Performance: A Structural Equation Modeling Approach. IUP Journal of Knowledge Management, 12 (3), pp. 17-41.

Wang, Z., Wang, N., and Liang, H. (2014). Knowledge Sharing, Intellectual Capital and Firm Performance. Management Decision, 52 (3), pp. 230-258.

Wu, C., Lee, C., and Tsai, L. (2012). Research on the Knowledge Sharing, Adventure Recreation and Performance of Information System R\&D Personnel. International Journal of Organizational Innovation, 5 (1), pp. 176-202.

Wu, Y., and Zhu, W. (2012). An Integrated Theoretical Model for Determinants of Knowledge Sharing Behaviours. Kybernetes, 41 (10), pp. 1462-1482.

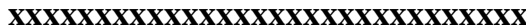

